\title{
URUGUAY 2017: REACTIVACIÓN ECONÓMICA Y NUEVOS CONFLICTOS POLÍTICOS
}

\author{
Uruguay 2017: Economic Recovery and New Political Conflicts
}

\section{FABRICIO CARNEIRO}

Universidad de la República, Uruguay

\section{FEDERICO TRAVERSA}

Universidad de la República, Uruguay

\begin{abstract}
RESUMEN
El año 2017 se anticipaba como un posible un punto de inflexión para el modelo económico, social y político que lleva adelante el partido gobernante Frente Amplio desde 2005. El escenario político y el económico se presentaban particularmente delicados para el gobierno, tanto en el plano doméstico como en el internacional. Sin embargo, el año 2017 se cerró con un crecimiento económico inesperado, mejora de algunos indicadores sociales y el retorno de las mayorías parlamentarias que el Frente Amplio había perdido durante 2016. Al mismo tiempo nuevos conflictos se abrieron para el gobierno, sobre todo en el frente interno. Entre ellos se destacaron el proceso que condujo a la renuncia del vicepresidente de la República Raúl Sendic, los procesos de negociación para la firma de un acuerdo marco de inversión entre el Estado uruguayo y la empresa finlandesa UPM, el intento de reforma de la "caja militar" y la generación de acuerdos para la llamada ley de "cincuentones". Por distintas razones, estos conflictos produjeron tensiones al interior del Ejecutivo o del partido de gobierno, que finalmente se saldaron en el correr del año. Como ha sucedido en otras ocasiones, la interna política del Frente Amplio se reveló como un ámbito especialmente relevante para la negociación y la toma de decisiones relacionadas con la resolución de conflictos entre el Ejecutivo y el partido de gobierno.
\end{abstract}

Palabras clave: Uruguay, Frente Amplio, mayoría parlamentaria, política económica

\begin{abstract}
The year 2017 seemed a possible turning point for the economic, social and political model of the ruling party, Frente Amplio, which has governed Uruguay since 2005. The political and economic scenario was particularly sensitive for the government, both at the domestic and international levels. However, the year closed with unexpected economic growth, the improvement of some important social indicators, and the return of the parliamentary majorities that the Frente Amplio had lost in 2016. At the same time, new conflicts opened for the government, especially on the internal front. Among them, the process that led to the resignation of the Vice President of the Republic Raúl Sendic, the negotiation processes for securing of an investment by the Finnish company UPM, the attempt to reform the "Caja Militar," and the generation of agreements for the so-called "Ley de los Cincuentones." For different reasons, these conflicts produced tensions within the Executive branch of the government, which finally settled over the course of the year. As has happened on other occasions, the Frente Amplio's internal politics were revealed as an especially relevant area for negotiation and decision-making related to the resolution of conflicts between the Executive and the governing party.
\end{abstract}

Keywords: Uruguay, Frente Amplio, parliamentary majority, economic policy 


\section{INTRODUCCIÓN}

El año 2017 se anticipaba como un potencial punto de inflexión para la administración del presidente Tabaré Vázquez, tercera consecutiva del partido Frente Amplio, que desde 2005 gobierna en Uruguay. En el plano económico, luego de catorce años de expansión entre 2003 y 2016 - con tasas de crecimiento ubicadas muy por encima de la media histórica del país - se esperaba que el año 2017 estuviera marcado por un magro desempeño de la economía uruguaya. Así lo hacían suponer la notoria ralentización reciente de los dos grandes vecinos, Argentina y Brasil, sumada a una caída en 2017 de los precios de los productos exportados por Uruguay y la necesaria implementación, por parte del gobierno, de un paquete de ajuste con el objetivo de reducir el déficit fiscal.

Por su parte, en el plano político, el partido gobernante debió comenzar el 2017 con un escenario bastante inhóspito, tanto en la rama parlamentaria como en la ejecutiva. La imagen del vicepresidente Raúl Sendic y la del gobierno en general habían sufrido un sensible desgaste durante todo 2016 y el nuevo año no estuvo exento de nuevos conflictos al interior del Ejecutivo. En un contexto de gestión que priorizó la reducción del déficit fiscal, la resolución de algunos problemas puntuales vinculados con el desequilibrio fiscal tensaron el funcionamiento del Ejecutivo y motivaron incluso la amenaza de renuncia de una parte sustancial del equipo económico. Mientras tanto, en la arena legislativa el gobierno se encontró por primera vez desde el año 2005 sin mayorías parlamentarias.

No obstante estos antecedentes, 2017 transcurrió sin mayores sobresaltos para el gobierno de Tabaré Vázquez. En contra de los pronósticos más pesimistas, la economía retomó su crecimiento; el país consiguió además, luego de muchos años, un importante superávit en el comercio exterior y redujo sensiblemente la inflación, ubicándola por primera vez en muchos años dentro del rango meta. Sin embargo existe todavía preocupación por la situación fiscal, pues a pesar de reducirse el déficit en aproximadamente 0,5\% del PBI, aún continúa en niveles altos. Asimismo existen algunos recaudos en torno a la tasa de desempleo, que se encuentra ahora ubicada un par de puntos porcentuales por encima de los niveles excepcionalmente bajos que mostró hasta 2014.

En el plano político, el proceso de deterioro de la imagen del vicepresidente Raúl Sendic se saldó finalmente con su renuncia en el mes de septiembre de 2017. De este hecho político pueden hacerse dos lecturas. En primer lugar, el partido de gobierno pierde a una figura política que hace tan solo cuatro años obtuvo una importantísima votación en la interna partidaria y que parecía destinado a renovar el elenco político de la izquierda. Al mismo tiempo el gobierno resolvió, con un buen plazo de antelación a las elecciones de 2019, una crisis que golpeaba sistemáticamente su imagen, por lo que asumió la vicepresidencia de la República Lucía Topolansky, primera mujer en la historia en ocupar el cargo.

También en el mes de septiembre de 2017 el gobierno retomó inesperadamente las mayorías parlamentarias, luego de la renuncia a su banca del diputado Gonzalo 
Mujica, que se había alejado del partido de gobierno en 2016. Por su parte, en el Partido Nacional — principal formación política de oposición - se registraron realineamientos internos y anuncios de precandidaturas presidenciales para las elecciones de 2019. La democracia uruguaya y su desempeño económico y social reciente fueron una vez más destacados en el plano internacional en 2017, y en este marco institucional general las elecciones se anticipan especialmente competitivas. El devenir económico y social de los próximos meses, en particular el transcurrir de la séptima ronda de Consejos de Salarios de 2018, puede ser determinante para la ratificación electoral del modelo económico y político que el Frente Amplio ha instrumentado desde el gobierno.

A continuación se analizan con más detalle los principales eventos económicos, sociales y políticos registrados durante 2017. El artículo está organizado en seis secciones. El primero de estos apartados se dedica a repasar el desempeño de la economía. La segunda sección resume la coyuntura social y la tercera el panorama político y electoral. La cuarta se aboca al análisis del funcionamiento del parlamento y la última, al accionar del Ejecutivo. El artículo finaliza con unas breves conclusiones.

\section{ECONOMÍA Y BIENESTAR SOCIAL}

El año 2017 se avizoraba particularmente difícil para la pequeña economía uruguaya, debido al comportamiento desfavorable de algunos factores externos que la impactan fuertemente y que potencialmente afectan a una larga serie de indicadores relativos al bienestar social. Desde el año 2005, las sucesivas administraciones del Frente Amplio (en particular la primera de ellas) han desarrollado una institucionalidad redistributiva que ha permitido una continua redistribución del ingreso a lo largo de casi quince años, con significativas caídas en los índices de pobreza e indigencia y una moderada pero sostenida caída en la desigualdad (Gráficos 5 y 6).

El funcionamiento de estas instituciones redistributivas - especialmente la negociación laboral colectiva ${ }^{1}$ y el nivel de ingresos fiscales que posibilita el gasto e inversión social- se encuentra potencialmente sujeto a tensiones, como consecuencia de estar montadas sobre una pequeña economía abierta, que todavía exporta fundamentalmente bienes primarios (Traversa 2009). En tal sentido, el contexto reciente ha sido difícil para Uruguay, en tanto los precios de los principales productos exportados por el país experimentaron un importante retroceso desde los niveles alcanzados en el año 2011 y el valor total de las exportaciones cayó un 7,3\% durante 2016.

Uruguay ya había tenido mecanismos de fijación salarial tripartitos (Consejos de Salarios) entre 1943 y 1967, y entre 1985 y 1992. En 2009 el gobierno del Frente Amplio promulgó nuevas leyes de negociación colectiva que sustituyen a la ley de 1943, en ese momento se abandonó la homologación de los convenios por parte del gobierno y se pasó a un esquema donde para su aprobación cada una de las delegaciones sociales cuenta con dos votos, mientras que el gobierno tiene tres. 
Gráfico 1. Uruguay, tipo de cambio real efectivo global (a), regional (b) y extrarregional (c) $(2010=100)$

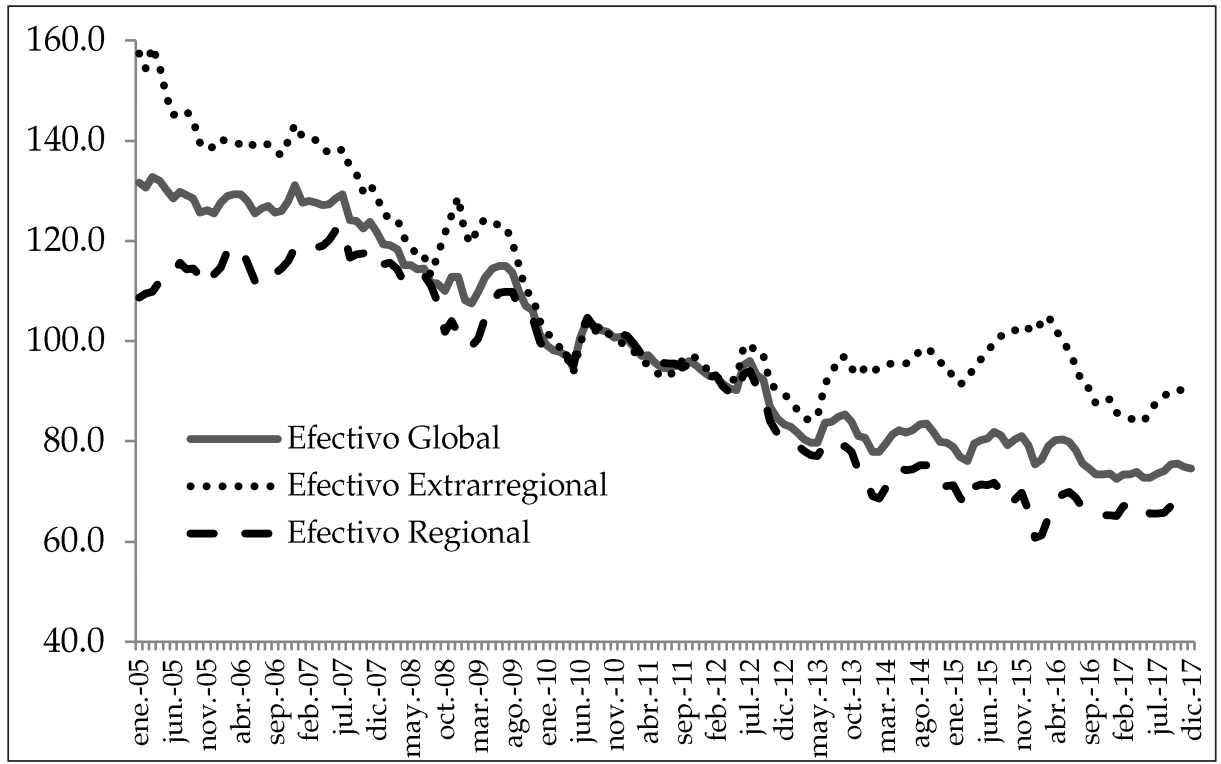

Fuente: elaboración propia con datos del Banco Central del Uruguay

(a) El tipo de cambio es la relación entre los índices de precios al consumo de los principales socios comerciales, con relación a la economía doméstica, expresados en una misma moneda.

(b) Los países incluidos en el extrarregional son: Estados Unidos, España, Italia, Alemania, Reino Unido y China, su ponderación en el índice refleja su participación en el comercio de bienes con Uruguay en 2009.

(c) Los países incluidos en el regional son: Argentina y Brasil y su ponderación en el índice refleja su participación en el comercio de bienes con Uruguay en 2009.

Asimismo, Brasil y Argentina, los grandes vecinos y socios comerciales del Uruguay, sufren un severo estancamiento económico desde hace un par de años, sumado a un cambio de orientación política en sus respectivos gobiernos. Finalmente la caída de las tasas de interés en los países centrales ha favorecido la entrada de divisas, que si bien facilitan el crédito, aprecian el peso uruguayo (Gráfico 1) y podrían afectar el comercio exterior como sucedió antes de la crisis de 2002. ${ }^{2}$

Sin embargo, en 2017, a pesar del contexto internacional general, el valor total de las exportaciones uruguayas creció un $12,8 \%$, gracias a un importante incremento en el total de los volúmenes exportados, que permitió revertir una nueva caída de un $7 \%$, en los precios de las exportaciones del país. Gracias a este buen desempeño de las exportaciones, la cuenta corriente y de capital registró un superávit de 1,6\% del PBI, el primero de esta magnitud en muchos años. Finalmente y contra las expectativas más sombrías, el producto volvió a crecer 
un $2,7 \%$ en 2017 , mientras que la tasa de desempleo se mantuvo estable en un $7,5 \%$.

Gráfico 2. Uruguay, evolución de la deuda bruta y neta del sector público global, como porcentaje del producto interno bruto (2004-2017)

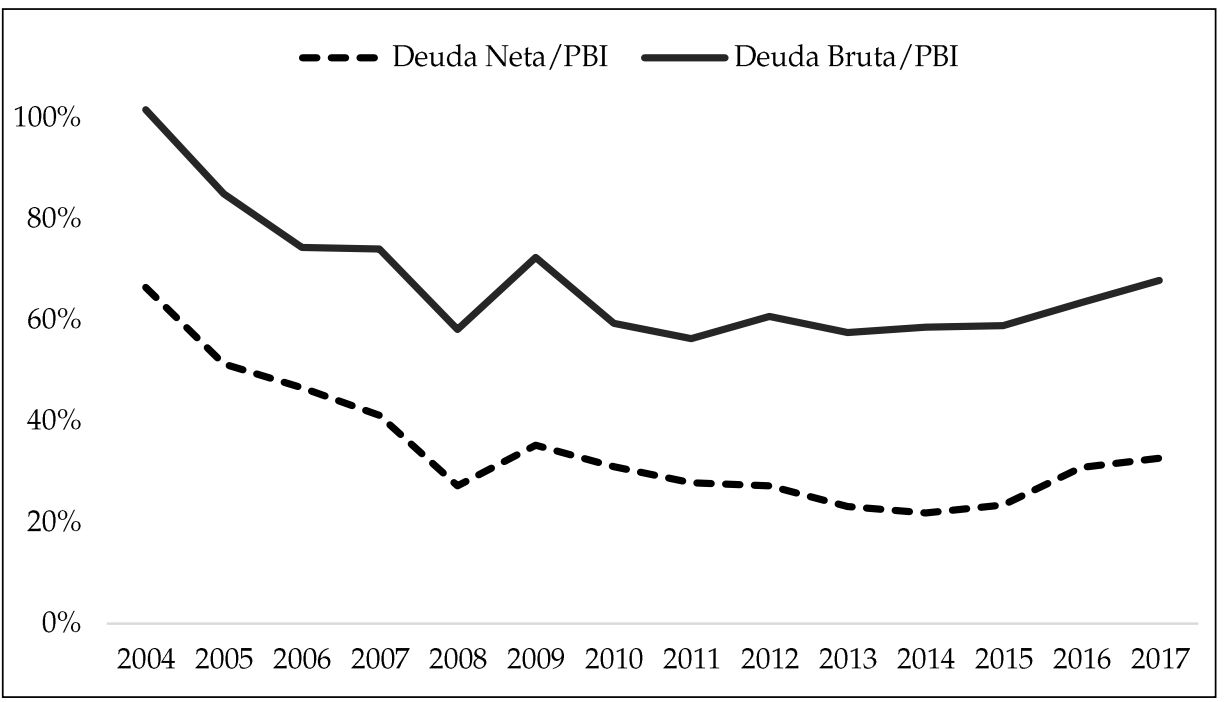

En materia monetaria y fiscal, por su parte, el 2016 había mostrado algunas vulnerabilidades importantes: la inflación había estado un poco por encima del rango meta y el déficit fiscal fue alto, ubicándose en torno del $4 \%$ del Producto. Con este panorama general y con el objetivo de reducir el déficit y controlar la inflación, el gobierno definió en 2016 la aplicación en el siguiente año de un paquete de "consolidación fiscal"3 (Bogliaccini y Queirolo 2017). Como resultado, la inflación se redujo a un 6,7\% en 2017, ubicándose luego de varios años dentro del rango meta del gobierno, mientras que el déficit fiscal se redujo a 3,5 \% del PIB (aún por encima de lo esperado). Asimismo, la deuda pública tuvo un nuevo leve incremento en 2017, que está relacionado con seguridad con este déficit fiscal. No obstante ello, la deuda soberana uruguaya está muy bien calificada internacionalmente, su volumen con relación al PIB es menor del que tenía hace una década (ver Gráfico 2), y las condiciones de su colocación en términos de moneda y plazos de vencimiento son francamente más equilibradas que al asumir el Frente Amplio el gobierno.

En materia de negociación laboral colectiva, el año 2017 marcó un compás de espera entre la sexta ronda de Consejos de Salarios, que finalizó casi

Las medidas que se aprobaron en 2016 tienen por objetivo final la convergencia a la meta de resultado fiscal del Sector Público Global de -2,5\% del PIB en 2019. Entre las medidas tomadas se destacan el aumento del impuesto a la renta de las personas físicas (IRPF), incremento de las tarifas públicas y medidas de recorte del gasto. 
completamente en 2016, y la séptima ronda que comienza en 2018 y será la más grande en la historia del país. Los convenios alcanzados en la sexta ronda se mantuvieron en general (72\%) dentro de los lineamientos sugeridos por el Poder Ejecutivo. Sin embargo, como señala Rodríguez (2016), el número de convenios alcanzados por consenso entre las tres partes (empresarios, trabajadores y gobierno) se redujo casi un $30 \%$ entre la quinta y la sexta ronda.

En opinión de Bogliaccini y Queirolo (2017), el menor número de convenios consensuados revela algunas dificultades en el diseño de la negociación colectiva uruguaya y anticipa algunos desafíos en relación con la contención de la demanda salarial en los sectores no transables, en especial en períodos de enlentecimiento económico. En particular el alza de los salarios podría repercutir negativamente en los niveles de empleo. En el caso uruguayo, se agrega a nuestro entender un factor crítico que agudiza el problema y que se relaciona con la apreciación del tipo de cambio, producto del fuerte impacto que suponen los flujos de divisas cuando ingresan en una economía pequeña y abierta como la uruguaya.

En la coyuntura reciente, la caída de las tasas de interés en las economías centrales ha favorecido una importante entrada de divisas con la consiguiente apreciación del peso uruguayo y el inevitable encarecimiento de la economía local en dólares. Una dinámica muy similar ya tuvo efectos negativos sobre el empleo en el pasado reciente de Uruguay, en particular entre los años 1999 y 2002 (Traversa 2003). Tal vez aquí resida el principal problema para los niveles de empleo en el corto plazo más que en los resultados de la negociación laboral colectiva -en general siempre progresivos y moderados- en tanto la economía se ha encarecido en términos relativos durante la última década (Gráfico 1).

Por otra parte, a pesar de las reservas que siempre pueden existir, el modelo de negociación colectiva en Uruguay, desde su reinstauración en 2005, ha sido francamente exitoso en función de los objetivos propuestos. ${ }^{4}$ Como se aprecia en el gráfico 3, el índice medio de salarios se ha ubicado siempre por encima de la inflación, permitiendo una gradual, sostenida y negociada recuperación del salario real durante más de diez años. Asimismo, la inflación se mantuvo durante todo el período en niveles moderados, que no superaron nunca la barrera de los dos dígitos, mientras que la producción creció de forma sostenida, a tasas que están muy por encima de la media histórica del país.

Por ejemplo el director general de la Organización Internacional del Trabajo (OIT), Guy Ryde, opinó durante su visita a Montevideo en 2017 que: "La negociación colectiva (...) ha podido producir resultados sumamente positivos en términos de salarios, de empleo, de equidad, también en términos de creación de empresas. Hay que tener muy presente todo lo positivo que tiene hoy en día lo que hoy existe en Uruguay" (El País, 14 de noviembre de 2017). 
Gráfico 3- Uruguay, evolución de salarios y de precios (2000-2017)

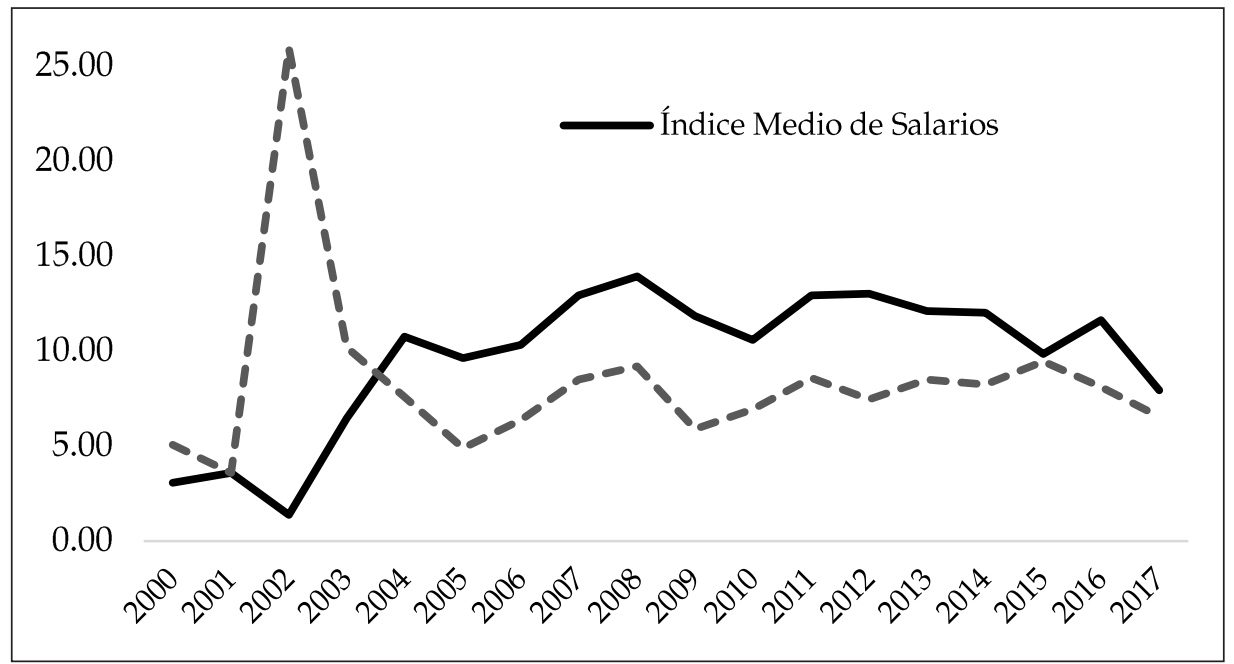

Fuente: elaboración propia con datos del Instituto Nacional de Estadística

Dada la evolución consistente del salario real, el crecimiento de la economía y el control inflacionario, solo pueden mantenerse algunos recaudos relacionados con los efectos de la negociación laboral sobre los niveles de empleo (Iversen 1999; Swenson 1989; Bogliaccini y Queirolo 2017). En el caso uruguayo, si se adopta una perspectiva de mediano plazo puede apreciarse que la mejora sostenida en el salario real durante más de una década estuvo combinada con una importante caída del desempleo (Gráfico 4). Es en los últimos dos o tres años que se produjo una leve caída en la tasa de actividad (pasó de 63,8\% en 2015 a 62,9\% en 2017) junto con un incremento del desempleo (relativamente estabilizado en tasas cercanas al 7,5\%).

Sin embargo, no es posible asegurar que este leve incremento reciente en los problemas de empleo pueda estar relacionado con la negociación colectiva en sí misma -durante años la negociación se relacionó con un aumento del empleo- más aún cuando existen otras explicaciones alternativas, como la anticipada con relación a la apreciación del tipo de cambio. No obstante estos resultados económicos recientes, que pueden verse como moderadamente positivos, el 2018 se presenta como un año clave para la negociación colectiva y para el futuro del modelo económico uruguayo en general. Por primera vez en la historia, se producirá la negociación concentrada de 227 consejos de salarios durante un año previo a las elecciones nacionales. En tal sentido, los riesgos para el gobierno son altos, pues del clima social instalado en los próximos meses dependerá en buena medida su suerte electoral.

Hasta el momento, los resultados obtenidos por las tres administraciones del Frente Amplio habilitarían a presentar al Uruguay como un caso excepcional, donde la izquierda se mantuvo en el gobierno quince años consecutivos, se 
redujo la pobreza y la desigualdad, al tiempo que la economía creció a tasas moderadas pero por encima del resto de sus países vecinos y con el desempeño del propio Uruguay en perspectiva histórica. En tal sentido, particularmente destacable fue la nueva caída en 2017 de la pobreza (7,9\% de las personas son pobres) y de la indigencia $(0,1 \%$ de las personas) que alcanzaron mínimos históricos. No obstante ello, algunas tendencias estructurales de esta pobreza, como su preocupante concentración en edades infantiles, no se ha revertido pese a una mejora general. ${ }^{5}$

Gráfico 4. Uruguay, evolución del Producto y el desempleo (2000-2017)

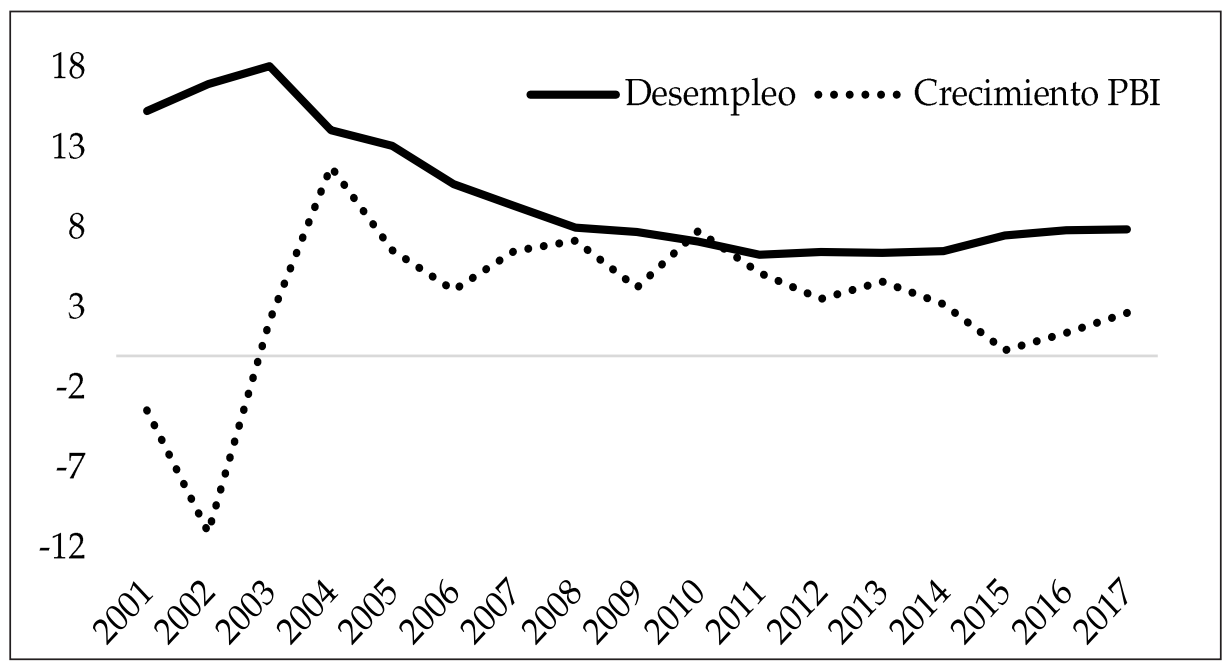

Fuente: elaboración propia con datos del Instituto Nacional de Estadística y Banco Central del Uruguay

Sin embargo, un escenario de conflictividad social en aumento podría ser particularmente complejo para el gobierno. Por esa razón la postura del movimiento sindical frente a la próxima ronda de consejo de salarios resulta particularmente crítica. Si privilegia una postura estratégica de mediano plazo, ${ }^{6}$ que busque consolidar mejoras laborales sin comprometer una agudización de la conflictividad, el escenario parece moderadamente optimista para las posibilidades electorales del Frente Amplio.

Se estima que el 15\% de los menores de edad eran pobres en 2017; si bien esta cifra implica una reducción drástica respecto del $59 \%$ de menores pobres en 2004, la pobreza continúa concentrándose fuertemente entre niños y adolescentes (Crónicas, 13 de abri de 2018)

6 En los últimos años el movimiento sindical ha conseguido un importante aumento en las tasas de sindicalización y mejoras en el salario real con reducción de la dispersión salarial, gracias a una deliberada estrategia de mejoras salariales especiales para los trabajadores con menores ingresos. Difícilmente estos resultados se habrían verificado sin la reintroducción de la negociación colectiva en 2005 y la continuidad de este modelo de negociación -por lo menos con estas características- depende con seguridad del resultado electoral en 2019. 
El sector empresarial, por su parte, luego de un período de relativa tregua, mantuvo durante la segunda mitad del pasado 2017 una postura crecientemente crítica del accionar del gobierno, en particular en lo que tiene que ver con la negociación laboral colectiva. ${ }^{7}$ Asimismo en los últimos meses del año pasado surgieron diversas advertencias desde el sector empresarial en relación con el tipo de cambio y sus efectos en la competitividad de la producción local. ${ }^{8}$ En tal sentido el gobierno sostiene que la política cambiaria es flexible y acompaña las tendencias internacionales.

Un análisis de la evolución reciente del tipo de cambio revela que durante 2017 los problemas no se agudizaron e incluso el tipo de cambio real se depreció muy levemente. Pero si se toman en cuenta los últimos diez años es notorio que el tipo de cambio real se ha apreciado con prácticamente todos los grandes socios comerciales (Gráfico 1).

Gráfico 5. Uruguay, evolución de la pobreza y la indigencia (2006-2017)

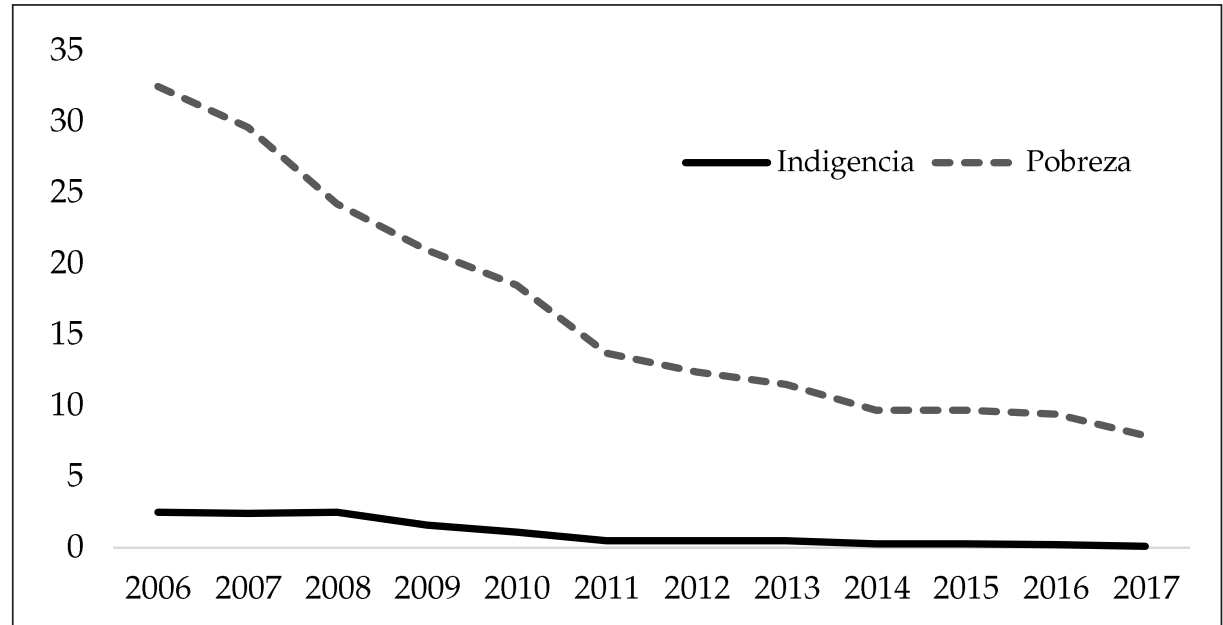

Fuente: elaboración propia con datos del Instituto Nacional de Estadística

7 Desde el año 2009 el sector empresarial uruguayo planteó quejas a la OIT en torno decreto 165/06 que reglamenta las ocupaciones de lugares de trabajo.

8 Desde la Confederación de Cámaras Empresariales se manifestaron en 2017 preocupaciones en torno a la competitividad de la producción nacional debido al aumento de los costos locales debidos a la apreciación del peso uruguayo. 
Gráfico 6. Uruguay, evolución de la desigualdad de ingresos medida por el Índice de Gini (2006-2017)

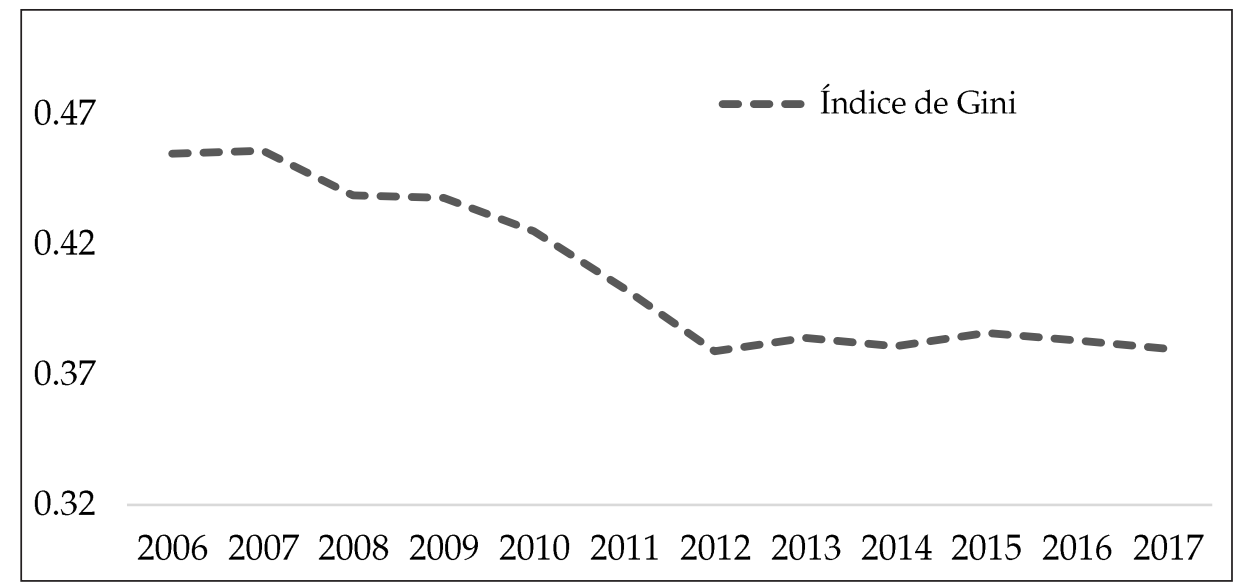

Fuente: elaboración propia con datos del Instituto Nacional de Estadística

En tal sentido, pueden efectuarse algunas puntualizaciones. En primer lugar, que el principal factor detrás de la apreciación del tipo de cambio es el ingreso de divisas y que el gobierno ha intervenido activamente para sostener el precio del dólar. En segundo lugar, dada la cercanía de las elecciones, no parece lógico que el gobierno haga esfuerzos más profundos por elevar el tipo de cambio. En tercer lugar, si bien la situación tiene algunos paralelos con lo sucedido a fines del siglo pasado, existe una diferencia sustancial en tanto la balanza comercial del país es hoy superavitaria y los problemas de empleo son mucho menores que en aquel entonces.

\section{COYUNTURA SOCIAL}

En los últimos años dos fenómenos sociales relativamente novedosos en el país se han vuelto relevantes. Los crecientes problemas de seguridad ciudadana se han convertido en una de las preocupaciones más importantes para la ciudadanía y han tenido una presencia constante en la agenda política de los partidos de oposición. Sin embargo, de forma latente a estas demandas de seguridad, Uruguay parece presentar un cambio en la estructura del crimen con incrementos de los delitos producidos por enfrentamientos entre grupos criminales rivales. En este sentido el año 2017 evidencia un destacado aumento de los homicidios provocados por enfrentamientos entre grupos criminales organizados vinculados con el narcotráfico. En 2013, 31\% de los homicidios tenían como causas precipitantes ajustes de cuentas o conflictos entre organizaciones criminales, mientras que en 2017 el porcentaje de homicidios por 
ese motivo llegó al 45\%. ${ }^{9}$ Este incremento de la prevalencia del narcotráfico en la estructura del delito debe ser incorporado en los diagnósticos sobre el aumento de la inseguridad en el país para poder realizar cambios en las estrategias de intervención que permitan una mayor eficacia de la política pública en seguridad ciudadana.

Un segundo fenómeno social novedoso en los últimos años es la reversión en la tendencia de los saldos migratorios negativos, lo que derivó en un mayor crecimiento de la población que el proyectado (Koolhas y Nathan 2013). Es posible identificar al menos dos factores que podrían explicar este resultado. Por un lado, el retorno de los uruguayos emigrados es el principal componente explicativo de los saldos migratorios positivos registrados en los últimos años (Koolhas y Nathan 2013). Por otro lado, particularmente a partir de 2015 un aumento de los flujos de inmigrantes regionales. ${ }^{10}$ Desde 2015 puede apreciarse un aumento en la solicitud de residencias permanentes por parte de inmigrantes de países del Mercosur y un cambio en el principal país de origen de estas solicitudes con Venezuela desplazando a Argentina como primer país de origen del flujo migratorio. ${ }^{11}$

\section{PANORAMA POLÍTICO Y ELECTORAL}

El año 2017 trajo consigo tres novedades importantes de cara la campaña electoral para la elección presidencial de 2019. En primer lugar, la resolución de uno de los problemas políticos más relevantes que enfrentaba el gobierno: la baja legitimidad del vicepresidente Raúl Sendic a causa de polémicas sobre su título universitario y su gestión en la empresa petrolera estatal ANCAP.

Desde que en febrero de 2016 una investigación periodística revelara que el entonces vicepresidente Sendic no tenía el título profesional con el que se presentaba y, posteriormente, se publicaran gastos no justificados utilizando la tarjeta corporativa de la empresa estatal, su legitimidad era muy baja y la figura de Sendic se convirtió en un problema que afectaba la imagen del Frente Amplio (Bogliaccini y Queirolo 2017).

En junio de 2017 el Tribunal de Conducta Política ${ }^{12}$ del partido de gobierno decide actuar de oficio para evaluar la conducta del vicepresidente y el 24 de julio realiza un informe muy desfavorable en donde señala que su actuación "compromete su responsabilidad ética y política, con incumplimiento reiterado

Los datos provienen del Observatorio de Criminalidad y Violencia del Ministerio del Interior.

10 En 2014 Uruguay aprobó la ley 19.254 que facilitó el acceso a la residencia permanente de familiares de uruguayos en el exterior y ciudadanos de los países del Mercosur.

11 Datos de la Dirección General para Asuntos Consulares y Vinculación, Ministerio de Relaciones exteriores.

12 Este Tribunal forma parte de la estructura del Frente Amplio. Es designado por el plenario nacional y una de sus funciones es evaluar las violaciones a las "normas de conducta definida para los frentemplistas que ocupen cargos políticos de confianza o de gobierno" (Estatuto Frente Amplio 2011, Art. 123). 
de normas de control" ${ }^{13} \mathrm{El}$ informe del Tribunal aumentó las presiones para la salida del vicepresidente y colocó todas las miradas en el plenario nacional del Frente Amplio, el máximo órgano decisor del partido, que debía pronunciarse sobre el informe y evaluar posibles sanciones.

La alternativa de sancionar a Sendic tensionaba la interna frenteamplista debido a que el sector del vicepresidente aumentó su poder en la interna del partido en los últimos años. Su sector fue el más votando en las elecciones primarias en junio de 2014 y fue el tercer sector más votado dentro del Frente Amplio en las elecciones nacionales de 2014, superando a sectores históricos dentro de la izquierda como el Partido Socialista y el Partido Comunista. En conjunto con el MPP, el sector del expresidente José Mujica, controlaban el 56\% de la Cámara Alta (9 de los 16 senadores, incluido el vicepresidente) y 62\% de la Cámara Baja (31 de los 50 diputados del FA) (Pérez y Piñeiro 2016).

El 9 de septiembre de 2017, en el marco del plenario, Sendic comunica su renuncia a la vicepresidencia. La renuncia descomprimió la interna del partido ya que modificó la agenda del plenario y se entendió que no tenía sentido evaluar sanciones. Finalmente, el 13 de septiembre el parlamento votó la renuncia del vicepresidente. Su salida resolvió un problema político importante que venía desgastando al gobierno. En particular, los gastos no justificados con la tarjeta corporativa de la empresa aportaban a la estrategia de la oposición de colocar el tema de la corrupción sobre la agenda política.

Como se observa en el Gráfico 7, la percepción de corrupción en el país parece haber ido en aumento y las polémicas por gastos con las tarjetas corporativas de las empresas estatales colocan en la agenda la corrupción como un tema de campaña electoral. Cabe agregar que el contexto regional de escándalos y procesamientos por el caso Odebrecht -aunque hasta el momento no parecen tener ningún vínculo con los casos de corrupción en el país- puede generar influencia sobre estas percepciones. 
Gráfico 7. Percepción de corrupción
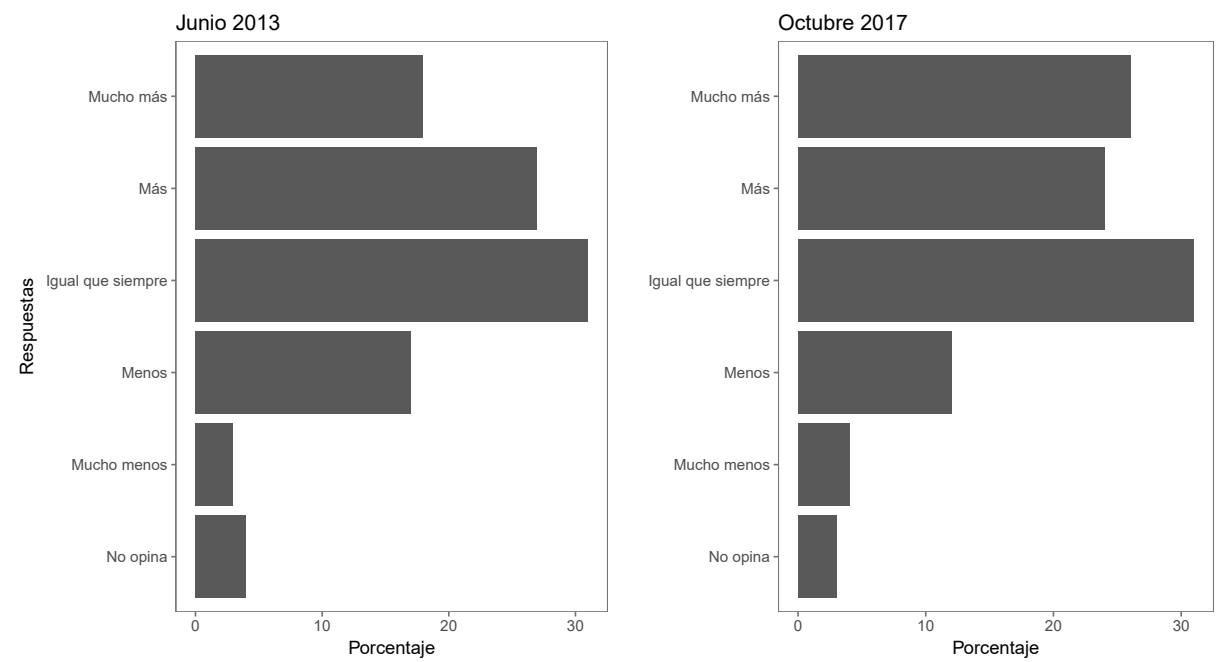

Pregunta: En el Uruguay de hoy, ¿hay la misma corrupción de siempre, hay más corrupción que antes o hay menos? Fuente: Cifra 2017.

Es importante señalar que el episodio con Sendic podría tener consecuencias de más largo plazo al posicionar en la agenda social y política el problema del control de los gastos discrecionales en los organismos públicos y la mejora en los mecanismos de rendición de cuentas del Estado. En este sentido, este caso podría analizarse como un conflicto de principal-agente. La corrupción sería el producto de una asimetría de información entre el principal (en este caso la ciudadanía) y el agente (el gobernante). La implicancia de política pública de este esquema para reducir la corrupción es clara. Afectar las motivaciones del agente para incurrir en este tipo de comportamiento mediante mecanismos de control que limiten la discrecionalidad del agente, mejorar los niveles de rendición de cuentas para maximizar la probabilidad ser detectado e incrementar las sanciones de incurrir en este tipo de actividades para aumentar los costos de este comportamiento (Persson et al. 2012). Tomando en cuenta la importancia que ha adquirido el tema, es esperable que en los próximos años Uruguay realice algunas reformas institucionales en esta línea.

En segundo lugar, comenzó a perfilarse la competencia interna entre los líderes del Partido Nacional, el principal partido de oposición y el único en condiciones de disputarle la continuidad en el gobierno al Frente Amplio. En junio de 2017 Jorge Larrañaga, actual senador y líder de Alianza Nacional, anunció su candidatura a la presidencia para las elecciones de 2019. Larrañaga es un líder importante dentro del partido ${ }^{14}$ pero su postulación llamó la atención debido a que en las elecciones

14 Alianza Nacional es el segundo sector más importante dentro del Partido Nacional detrás de Todos (herrerismo), el sector del Luis Lacalle Pou actual senador y último candidato a la presidencia por el partido en las elecciones presidenciales de 2014. 
internas de junio de 2014, después de una sorpresiva derrota frente a Luis Lacalle Pou -el candidato presidencial del Herrerismo-, el histórico líder de Alianza Nacional brindó un discurso en el cual parecía que esa sería su última postulación presidencial.

Por otro lado, un conjunto de intendentes ${ }^{15}$ electos dentro del sector de Larrañaga comenzó a organizar una tercera opción dentro del partido para las elecciones de 2019. En este escenario, y de no existir acuerdos entre ambos grupos, la postulación de Larrañaga podría fragmentar el voto de los sectores minoritarios dentro del Partido Nacional de cara a las elecciones primarias de 2019, aumentando las posibilidades de Luis Lacalle Pou, quien no parece contar con opositores a la interna de su sector.

En tercer lugar, el surgimiento en los días finales del año de un conflicto con productores agropecuarios, que fue inesperado para el gobierno y que coloca en la agenda de la campaña electoral las tensiones distributivas del modelo económico forjado en los trece años de gobierno de izquierda.

A fines de noviembre, la Asociación Rural del Uruguay (ARU), La Federación Rural (FR), la Comisión de Fomento Rural (CFR) y las Cooperativas Agrarias Federadas (CAF) solicitaron una reunión con el presidente Tabaré Vázquez para plantearle los problemas que venían acumulando diferentes actividades del sector agropecuario. El mandatario pospuso la reunión con las asociaciones rurales por motivos de agenda ${ }^{16}$ comprometiéndose a mantener una reunión en febrero o marzo de 2018. El 5 de diciembre los productores elevaron una nueva nota a presidencia insistiendo en la necesidad de un encuentro y, ante la falta de una respuesta de reunión inmediata por parte del presidente, comenzó el impulso inicial a la organización de productores rurales por fuera de las principales gremiales.

Los autodenominados "productores autoconvocados" comenzaron a organizarse y a evaluar movilizaciones en los días finales del año. La primera movilización importante tuvo lugar el 10 de enero de 2018 con vigilia en los costados de las rutas y amenazas de piquetes. El gran acto de movilización lo realizaron el 23 de enero en la ciudad de Durazno donde, bajo la consigna "un solo Uruguay", el movimiento presentó una plataforma de reivindicaciones que entre sus puntos incluían: disminuir el gasto del Estado, aprobación de una ley fiscal, bajas en los costos de combustible y energía eléctrica, renegociación de deudas y eliminar el atraso cambiario. La convocatoria a la movilización en un principio era realizada por grupos vinculados específicamente con la producción agropecuaria, pero con el paso de los días se fueron sumando otras organizaciones empresariales por fuera del sector. ${ }^{17}$

15 Los intendentes son Sergio Botana (Cerro Largo), Eber Da Rosa (Tacuarembó), Enrique Antía (Maldonado) y Dardo Sánchez (Treinta y Tres).

Página de Presidencia, 12 de enero de 2018.

17 Por ejemplo, la Agrupación de Médicos por el Cambio, la Asociación Nacional de Broadcasters Uruguayos (ANDEBU) y la Cámara Inmobiliaria de Punta del Este. 
La movilización de los productores agropecuarios tomó por sorpresa al gobierno por dos motivos. Por un lado, la baja de la inflación en 2017 y el retorno a una senda de crecimiento económico generaron expectativas que contrastaban con la imagen de crisis del sector agropecuario que el movimiento de productores rurales promovía en su discurso. Por otro lado, los productores rurales, además de ser un sector lejano a la coalición de apoyo del gobierno -están más vinculados con el Partido Nacional que con el Frente Amplio- son sectores que generalmente se venían manifestando en política por dentro de sus organizaciones tradicionales y dentro de los partidos. La innovación política de los autoconvocados es su movilización directa por fuera de estas estructuras de representación de intereses.

\section{PODER LEGISLATIVO: EL RETORNO DE LA MAYORÍA}

La novedad más importante en el Poder Ejecutivo y en la Cámara de Senadores fue el cambio en la vicepresidencia como consecuencia de la renuncia del vicepresidente Raúl Sendic. Con la renuncia, el cargo de vicepresidente debió ser ejercido por el senador titular más votado de la lista más votada. ${ }^{18}$ Siguiendo el mandato constitucional, la vicepresidencia fue ocupada por la senadora del MPP (Movimiento de Participación Popular) Lucía Topolansky, convirtiéndose en la primera mujer en ejercer ese cargo en la historia del país.

El cambio en la vicepresidencia fue importante para la agenda de gobierno debido a la función que cumple en el parlamento. El vicepresidente ejerce como presidente del Senado y la asamblea general. En esa doble función la vicepresidencia se encarga de coordinar las relaciones entre el Ejecutivo y el Legislativo, llevando la agenda del gobierno en el parlamento al participar en las reuniones de gabinete al mismo tiempo que cuenta con poder de agenda en el Legislativo (Chasquetti 2014: 28). Como presidente del Senado, fija el orden del día en consulta con los coordinadores de bancada y distribuye los proyectos de ley entre las diferentes comisiones. En el proceso legislativo, recibe los proyectos del gobierno y los deriva a las cámaras para su estudio.

Con la figura de vicepresidente deslegitimada, la función de articulación entre la oposición y el gobierno -e inclusive dentro del propio gobierno en la bancada de senadores- se fue desgastando, por lo que la salida de Sendic, en conjunto con la recuperación de la mayoría parlamentaria, podría acelerar la agenda de gobierno en el Legislativo en los últimos dos años de mandato.

18 El senador más votado de la lista más votada en la elección de 2014 fue el expresidente José Mujica. Como Mujica no puede ejercer la presidencia de la República debido a la prohibición constitucional de reelección inmediata, la vicepresidencia debió ser ejercida por el segundo más votado en la lista mayoritaria del senado (Botitnelli 2015). 
Cuadro 1. Proyectos presentados y leyes sancionadas en año legislativo 2017

\begin{tabular}{ccc}
\hline & Proyectos presentados & Leyes sancionadas \\
\hline Poder Legislativo & $60 \%(171)$ & $35 \%(17)$ \\
Poder Ejecutivo & $40 \%(113)$ & $65 \%(31)$ \\
\hline Total & $100 \%(284)$ & $100 \%(48)$ \\
\hline
\end{tabular}

Fuente: Programa de Estudios Paralamentarios (PEP): https:/ / parlamentosite.wordpress.com

En 2017, al igual que en los dos primeros años de gobierno, la agenda de leyes sancionadas estuvo dominada por el Poder Ejecutivo aunque, en comparación con esos años, existió una mayor participación del Legislativo en el origen de los proyectos que finalmente se convirtieron en ley.

Una segunda novedad importante para la agenda del gobierno en el parlamento fue el retorno de la mayoría parlamentaria con la renuncia del diputado Gonzalo Mujica a su banca. El diputado Mujica se había alejado del partido de gobierno en 2016 pero renunció a su banca en septiembre de 2017 (ver Bogliaccini y Queirolo 2017). 
Gráfico 8. Eficacia legislativa

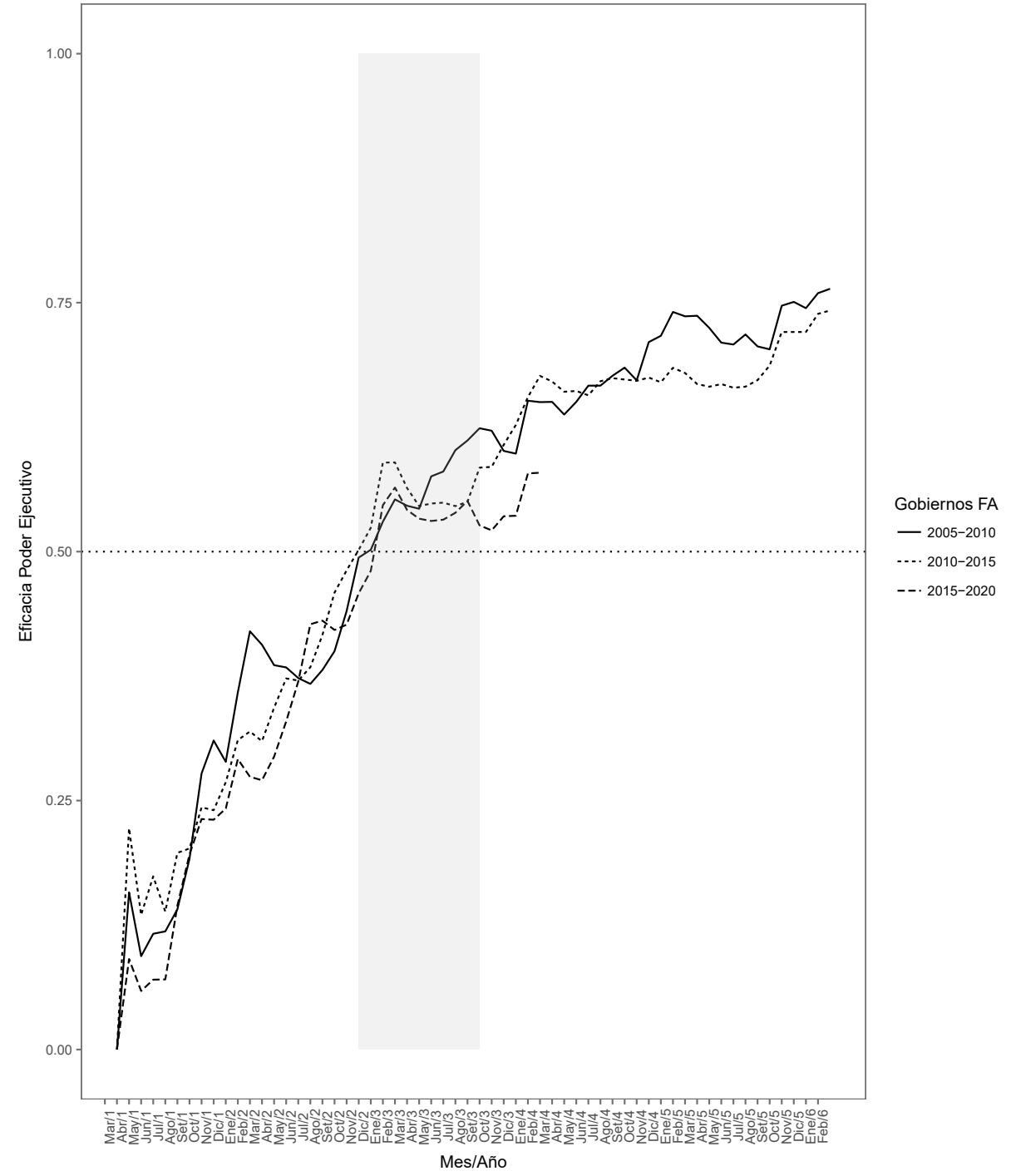

Fuente: Programa de Estudios Parlamentarios (PEP): https:/ / parlamentosite.wordpress.com

Como se observa en el Gráfico 8, la falta de mayorías no fue un impedimento para que el Poder Ejecutivo (PE) continuara con su agenda legislativa, aunque disminuye el ritmo de aprobación de sus proyectos. A febrero de 2018, la eficacia del PE en la aprobación de leyes es de 57,9\%, mientras que en el mismo período en los dos gobiernos anteriores, con mayoría parlamentaria, la eficacia era de $65 \%$-en febrero de 2008- y 67,6\% -en febrero de 2013-. Como se observa, en enero de 2017, la eficacia parlamentaria supera 50\%, desciende en marzo de 2017 para después crecer a un ritmo más lento en los meses finales del año. La zona resaltada en gris -diciembre de 2016 hasta septiembre de 2017- son los 
meses en donde el oficialismo perdió la mayoría parlamentaria en la Cámara de Diputados y como puede observarse existió una leve disminución en la eficacia parlamentaria del PE en los primeros meses después del alejamiento definitivo del diputado Mujica y posteriormente un enlentecimiento en su crecimiento.

Ante la pérdida de mayoría parlamentaria, el gobierno impulsó mayores negociaciones con algunos sectores de los partidos de oposición con bastante éxito. La ley de rendición de cuentas, por ejemplo, fue votada con el apoyo del diputado escindido Gonzalo Mujica y del diputado colorado Fernando Amado. Este último aceptó votar la rendición después de reunirse con el presidente Vázquez y acordar una reasignación del gasto en educación. Esta mayor negociación en la aprobación de los proyectos de ley tuvo como consecuencia un mayor tiempo de aprobación de los proyectos en comparación con el tercer año de gobierno de las dos legislaturas anteriores (Informe PEP 2017). El retorno de la mayoría parlamentaria en conjunto con la renovación en la vicepresidencia son cambios importantes para el gobierno porque le permiten acelerar su agenda en los años previos a la contienda electoral.

\section{PODER EJECUTIVO: CAMBIOS, AGENDAS Y TENSIONES}

El año 2017 mostró cierta recuperación en la evaluación de la gestión del presidente Tabaré Vázquez en comparación con 2016, aunque esta recuperación parece derrumbarse drásticamente en la medición de los primeros meses de 2018 (Gráfico 9). Aunque los datos de las distintas consultoras no son coincidentes, dos de las mediciones muestran un aumento de la aprobación de la gestión de Vázquez en el segundo semestre de 2017 (Factum y Cifra) pero también dos mediciones muestran un fuerte descenso de ella en el primer trimestre de 2018 (Equipos y Cifra). 
Gráfico 9. Evolución de la aprobación de la gestión del Presidente Tabaré Vázquez

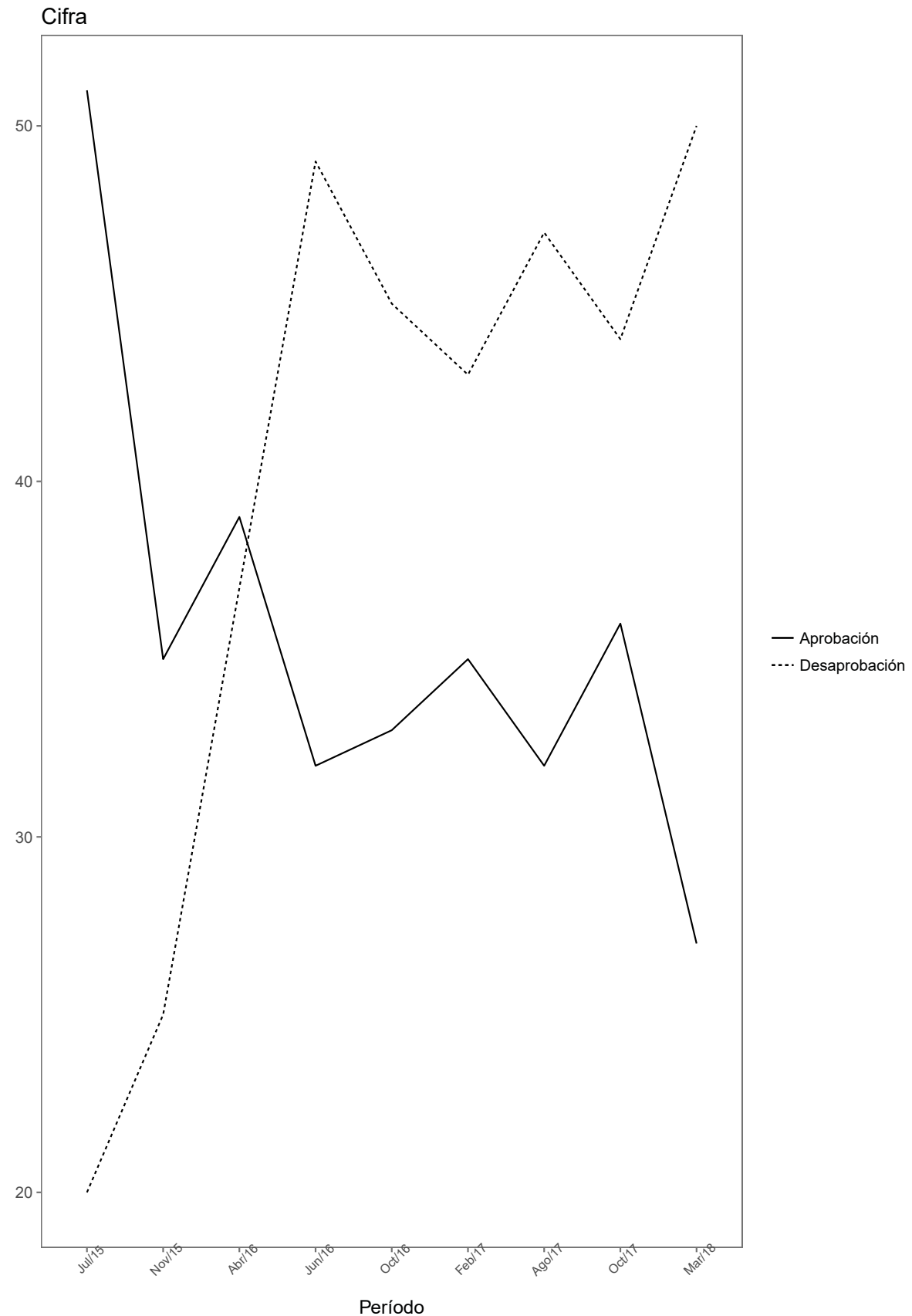


Gráfico 9. Evolución de la aprobación de la gestión del Presidente Tabaré Vázquez (cont:)

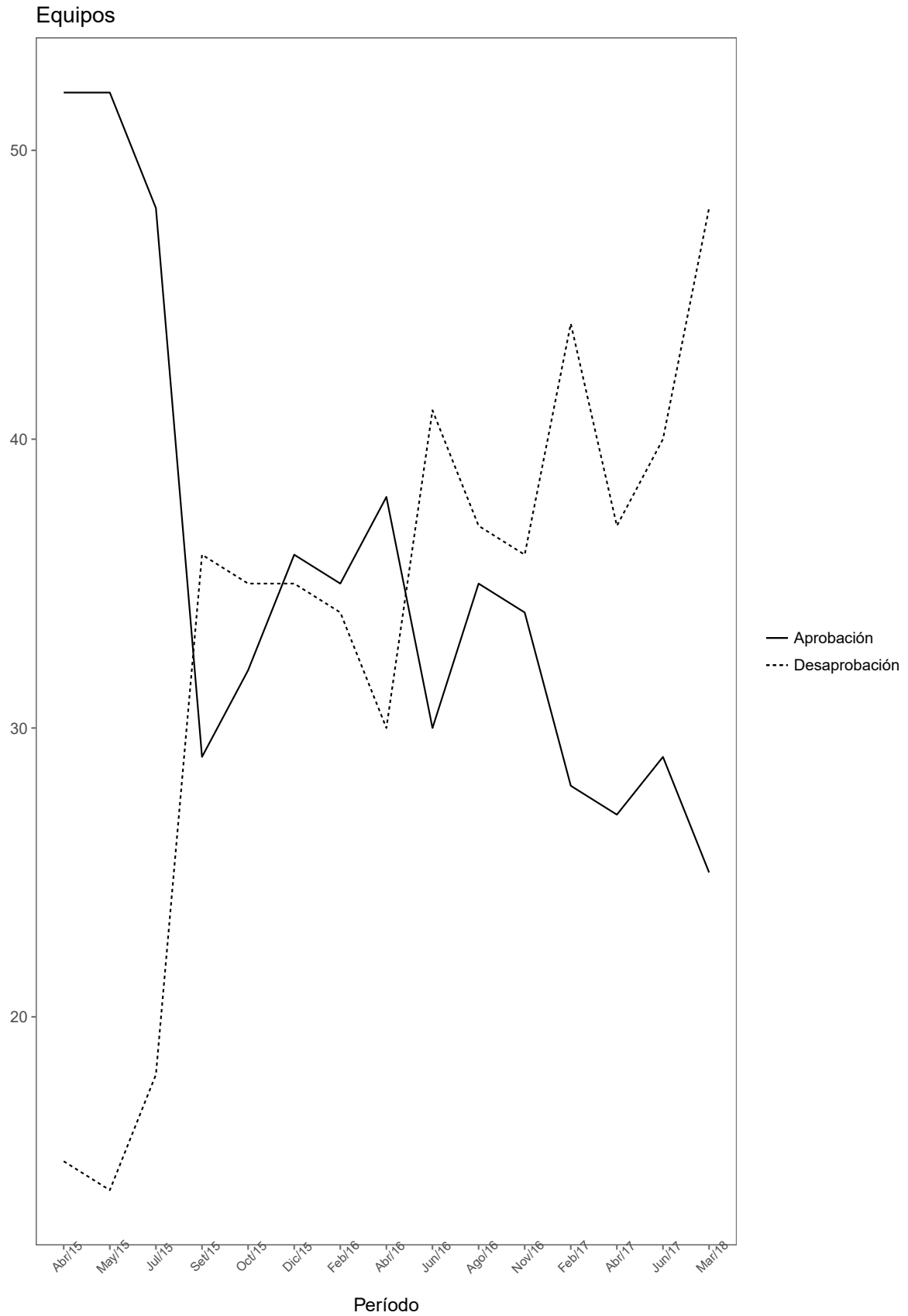


Gráfico 9. Evolución de la aprobación de la gestión del Presidente Tabaré Vázquez (cont.)

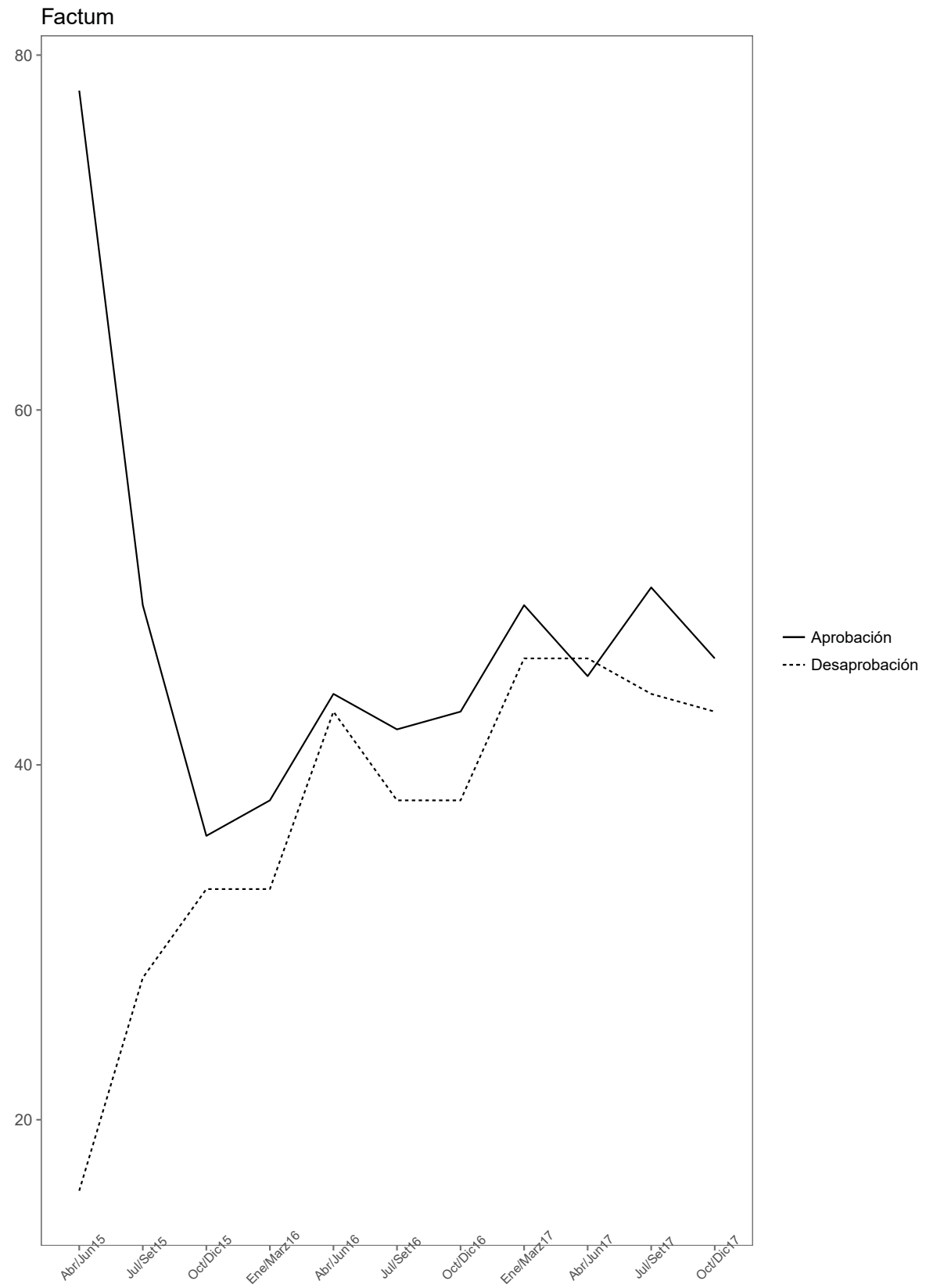

Período

Fuente: Banco de datos, Área de Política y Relaciones Internacionales, FCS-UdelaR. 
En relación con la agenda del Poder Ejecutivo, las prioridades estuvieron puestas en tres temas: la aprobación de un acuerdo marco de inversión entre el Estado uruguayo y la empresa finlandesa UPM, la reforma a la Caja Militar y la generación de acuerdos para llevar adelante la llamada "Ley de los Cincuentones". Los tres proyectos generaron fuertes tensiones en el Ejecutivo y el partido de gobierno pero dos de ellos lograron aprobarse en los meses finales del año.

El acuerdo de inversión entre la empresa UPM $^{19}$ y el gobierno establece la instalación de una nueva planta de celulosa -la tercera en el país- con una inversión que en estimaciones preliminares podría llegar a crear 8.000 empleos, generando un aumento del PIB cercano al 2\% (El Observador 2017, 7 de noviembre). La firma del acuerdo era una absoluta prioridad para el presidente y fue un proceso lento que no estuvo exento de contramarchas. A principios de año, Vázquez anunció desde una gira por Finlandia que en marzo se firmaba el acuerdo (Presidencia 2017, 13 de febrero), pero las negociaciones se extendieron. A fines de septiembre presentó su renuncia al cargo Andrés Masoller, director de Asesoría Macroeconómica del Ministerio de Economía y Finanzas (MEF) debido a las discrepancias con el acuerdo alcanzado con UPM y los costos fiscales que tendría la "Ley de los Cincuentones". La salida de Masoller evidenció las tensiones en la interna del Ejecutivo en torno a la prioridad marcada por Vázquez de firmar el acuerdo de inversión y las condiciones que la empresa establecía la Estado uruguayo.

A mediados de octubre, el mandatario había anunciado en varios medios que el acuerdo estaba próximo a cerrarse; sin embargo, se presentó púbicamente el 7 de noviembre. En el acuerdo alcanzado, la empresa deberá pagar unos 7 millones de dólares anuales como canon por la explotación en zona franca y el gobierno deberá otorgar una serie de exoneraciones impositivas como única vez en las operaciones de escisión y fusión de los accionistas de UPM (Contrato ROU-UPM 2017: 14).

El Estado además establece el compromiso de realizar una importante inversión en la infraestructura del transporte (Contrato ROU-UPM 2017: 19, 31, 35). En materia laboral, Uruguay se compromete a desarrollar, con la asesoría y supervisión de UPM, capacitaciones específicas para trabajadores. Además, se establecerá un protocolo de prevención y solución de conflictos en negociación conjunta entre el PIT-CNT, el Ministerio de Trabajo y UPM, cuyos acuerdos deberán incorporarse a la normativa laboral del país (Contrato ROU-UPM 2017: $41,43,44)$. El acuerdo alcanzado entre el gobierno y la empresa corresponde a la primera fase de negociación. En adelante comenzará la segunda fase, donde deberán comenzar las obras de infraestructura solicitadas y recién en la tercera

19 Es una multinacional finlandesa dedicada a la fabricación de pulpa de celulosa, papel y madera. En Uruguay esta empresa adquirió en 2009 las operaciones de la empresa Botnia ubicadas en la localidad de Fray Bentos en el departamento de Río Negro. 
fase la empresa resolverá definitivamente la inversión. ${ }^{20}$ Si se concreta, podría tener un fuerte impacto en los niveles de empleo, dada su magnitud. Pero la instalación de la empresa también presenta desafíos al Estado uruguayo, sobre todo en materia de control del impacto ambiental que pueda tener esta nueva planta de celulosa en el país.

A fines de mayo de 2017, el Poder Ejecutivo envió al parlamento dos proyectos de ley de reforma del sistema de previsión social militar: uno que busca implementar un impuesto transitorio durante 18 meses a las jubilaciones militares más altas para financiar el déficit en la seguridad social y otro proyecto que aumenta las edades de retiro, el monto y los años de aportes por parte de los militares, entre otras reformas.

La seguridad social de los militares es administrada por el Servicio de Retiros y Pensiones de las Fuerzas Armadas, denominado comúnmente como "Caja Militar". La reforma de la Caja entró en la agenda del Ejecutivo impulsada por el ministro de Economía Danilo Astori en la discusión sobre las medidas para disminuir el déficit fiscal. La Caja Militar presenta un déficit sistemático producto de un desbalance entre personal activo y pasivo que es solventado con trasferencias del Estado. En 2017, el Ejecutivo debió trasferir cerca de 550 millones de dólares a la Caja (Búsqueda 2018, 31 de enero), el equivalente a 0,8\% del PIB para cubrir las jubilaciones de unos 53.398 militares pensionistas y retirados. La oposición a los proyectos de ley en la interna del gobierno provenía tanto del Ejecutivo como del Legislativo. En el Ejecutivo, el Ministerio de Economía buscaba una reforma radical mientras que desde el Ministerio de Defensa se buscaba que la reforma solo afectara a nuevos efectivos (La Diaria 2017, 31 de mayo). Desde el Legislativo, el diputado por la Liga Federal Darío Pérez anunció que no votaría el proyecto de ley sobre impuestos a las jubilaciones por considerarlo inconstitucional. Frente a este escenario de falta de mayorías para las iniciativas, se postergó el tratamiento de estas leyes en el parlamento.

La ley 16.713, denominada "Ley de los Cincuentones", fue aprobada por el parlamento el 28 de diciembre de 2017. La ley habilita la desafiliación del régimen de jubilación de ahorro individual a las personas que al 1 de abril de 2016 tuvieran 50 o más años de edad y que hubiesen sido afiliadas de forma obligatoria a dicho régimen.

En 1995, durante la presidencia de Julio María Sanguinetti, se habilitó el régimen mixto de jubilación con la creación de un sistema de ahorro previsional de capitalización individual inspirado en el modelo chileno. Este sistema creó las Administradoras de Fondos de Ahorro Previsional (AFAPs) encargadas de administrar el ahorro individual de los trabajadores. A diferencia del resto de los reformadores de América Latina, los cambios de la seguridad social 
en Uruguay siguieron un patrón mixto de reformas, ya que si bien se creó un pilar de ahorro individual, la reforma matizó este pilar liberal manteniendo las "cajas-paraestatales" de profesionales, bancarios y militares, sumado a la creación de una AFAP pública que compite con las privadas en la captación de ahorros individuales (Alegre 2008: 146).

Si bien esta reforma fue tal vez uno de los cambios de inspiración neoliberal más importantes que se implementaron el país, en perspectiva comparada fue una de las reformas estructurales a la seguridad social más moderadas de América Latina (Brooks 2009: 139). La ley de creación de las AFAPs establecía que los trabajadores menores de 40 años con salarios mayores a 5 mil pesos -alrededor de 1.690 dólares a 2017- debían afiliarse obligatoriamente al sistema mixto. De esta forma, aportaban al Banco de Previsión Social (BPS) -sistema públicoel $15 \%$ de los primeros 5 mil pesos y al sistema privado el $15 \%$ del tramo de ingreso entre 5 mil y 15 mil pesos -unos 5.060 dólares a 2017 (Ley 16.713, art. 7)-. El problema de los "cincuentones" surge porque los trabajadores afiliados obligatoriamente al sistema mixto en 1995, al momento de retirarse más de 20 años después, tendrían una jubilación alrededor de 30\% menor a aquellos trabajadores que se les permitió continuar en el sistema público. ${ }^{21}$ Esta situación comprendería a unos 30 mil trabajadores.

Las causas de esta diferencia en las jubilaciones entre los regímenes son varias pero la principal es un tope a los aportes que estableció la ley de 1996. Antes de esta ley, los trabajadores aportaban a BPS por el total de su salario nominal pero, después de la reforma, se dispuso un límite de 5 mil pesos nominales a los aportes, independientemente de si esa persona hubiese tenido salarios mayores antes de 1996. Esto perjudicó a los trabajadores que antes del comienzo del régimen mixto habían realizado aportes al sistema público por salarios mayores al límite de la reforma. Primero, porque como el sistema público toma como cálculo para los pagos de jubilaciones los 20 mejores años de aportes o los últimos 10 años, los salarios anteriores a 1996 que estuvieran por encima del límite de la reforma no son tomados en cuenta. Segundo, porque estos trabajadores comenzaron a aportar al sistema privado más tarde que el resto de los trabajadores -simplemente porque antes no existía el sistema- y por lo tanto los aportes al régimen privado no compensan los aportes no reconocidos por el sistema público. ${ }^{22}$

Los trabajadores perjudicados por la creación del sistema mixto comenzaron a organizarse y a realizar protestas con apoyo de la central de trabajadores. Frente a este problema, el gobierno decidió crear una solución para este grupo.

21 La creación del sistema mixto determinó tres regímenes de jubilación de acuerdo con la edad de los trabajadores al momento de aprobarse la ley. Los trabajadores que estaban a cercanos a jubilarse lo hicieron por el régimen antiguo de reparto gestionado por BPS. Los que tenían entre 40 y 60 años se adhirieron a un régimen de transición y los menores de 40 años -los actuales cincuentones- son los que ingresaron al sistema mixto.

22 Trabajos de simulación han sugerido que soluciones alternativas al problema de los cincuentones pueden ser el reconocimiento de los aportes reales anteriores a 1996 o una postergación de alrededor de 5 años (de 60 a 65) de la edad de retiro (Forteza y Rossi 2016). 
El principal impulsor en el interior del Ejecutivo fue el ministro de Trabajo Ernesto Murro pero el proyecto que envió en el mes de julio el Ejecutivo al parlamento parecía que contaba con el respaldo de todos los ministros, inclusive del de Economía Danilo Astori. Sin embrago, en octubre, después de nuevas estimaciones acerca del costo fiscal del proyecto, ese respaldo se perdió.

La solución del Ejecutivo permitía la desafiliación del régimen privado por parte de los trabajadores perjudicados que todavía no se hubieran jubilado y el traspaso de los fondos aportados desde las AFAPs hacia un fideicomiso administrado por BPS. ${ }^{23}$ En principio el costo fiscal del proyecto se estimó en 2.500 millones de dólares en base a cálculos de BPS. Pero posteriormente, en una estimación del Ministerio de Economía, los costos ascendían a 3.700 millones, lo cual produjo la inmediata oposición del ministro de Economía al proyecto del Ejecutivo (El Observador 2017, 8 de diciembre). Frente a esta nueva estimación, el presidente Vázquez decidió no enviar modificaciones al proyecto, a pesar de la oposición del ministro Astori. Desde Asamblea Uruguay, el sector del ministro de Economía, comenzaron a advertir que sus legisladores no votarían el proyecto enviado e incluso versiones de prensa anunciaban que la renuncia de Astori al Ministerio estaba decidida si el proyecto no se modificaba (Búsqueda 2017, 13 de diciembre).

Para evitar un quiebre del gobierno, el proyecto del Ejecutivo comenzó a ser negociado por la bancada de diputados en la interna del partido de gobierno entre los distintos sectores. Finalmente, el 12 de diciembre se llegó a un acuerdo que contemplaba las diferentes posiciones. El proyecto acordado estableció una quita de $10 \%$ a las jubilaciones que recibirían los trabajadores por el régimen de transición, se incorporaron al beneficio 2.500 trabajadores ya jubilados y se regularon las comisiones que fijan las AFAPs hasta $50 \%$ por encima de la comisión más baja — que es la de la AFAP pública.

El costo fiscal de la ley modificada se estima que es $35 \%$ menor al proyecto original. La solución acordada es típicamente una solución de compromiso. El sector del ministro de Economía logró bajar el costo del proyecto al establecer una quita del 10\% en las jubilaciones, mientras que los sectores más cercanos a las posiciones de la central sindical lograron limitar las comisiones de las AFAPs e incorporar a trabajadores ya jubilados. Finalmente, el proyecto fue aprobado en Diputados con apoyo de los legisladores del partido del gobierno, Unidad Popular y una parte de los legisladores del Partido Nacional y Colorado. En senadores, apoyaron el proyecto los legisladores oficialistas y el sector Alianza Nacional dentro del Partido Nacional.

El comportamiento de la coalición de gobierno en torno de la "Ley de los Cincuentones" muestra de forma clara la particularidad del Frente Amplio como organización. A diferencia de otros partidos en la región, el FA es un 
actor que tiene influencia en las decisiones de gobierno y constituye una arena de discusión política y negociación (Rosenblatt et al. 2016), por lo que la izquierda uruguaya al momento de gobernar debe enfrentar constreñimientos internos y externos (Luna 2010). Los constreñimientos internos son producto de las distintas fracciones partidarias que buscan influir sobre las decisiones de gobierno y los externos vienen dados en gran medida por la alianza que el FA continúa manteniendo con las organizaciones de trabajadores. Para mantener estos equilibrios precarios, cada vez que surgen discrepancias internas, la organización partidaria pone en marcha agendas de negociación dentro del partido entre los distintos sectores y fuera del ámbito partidario con los actores sociales. En este sentido, las tensiones que generaron los tres temas de agenda del Poder Ejecutivo con el partido y sus aliados sindicales representan el funcionamiento típico que ha tenido el Frente Amplio como organización en sus vínculos con el gobierno y los actores sindicales desde que llegó al gobierno en 2005. Sin embargo, si en los próximos años las restricciones económicas se vuelvan más importantes y aumentan las discrepancias entre los diferentes sectores del partido en torno a las opciones de política económica, la capacidad de articulación entre partido, gobierno y sindicatos podría verse seriamente desafiada.

\section{CONCLUSIONES}

El transcurrir del año 2017 en Uruguay se reveló menos problemático para el gobierno de lo que se anticipaba. En el plano económico la tasa de crecimiento fue mayor a la esperada, la inflación cayó sensiblemente y las exportaciones crecieron fuertemente. No obstante, el déficit fiscal es aún alto y existen algunos recaudos en torno a la tasa de empleo que disminuyó luego de 2014. Por su parte, la pobreza y la indigencia volvieron a caer sensiblemente en 2017, así como la desigualdad, conformando un panorama de avance en materia de indicadores sociales.

En un plano estructural, la institucionalidad redistributiva que el Frente Amplio comenzó a montar desde su primer gobierno en 2005 parece seguir dando buenos resultados en materia de indicadores sociales. ${ }^{24}$ No obstante ello, los límites estructurales (Traversa 2009) que impone la pequeña economía uruguaya son hoy visibles. En tanto el país no experimente una transformación más profunda de su estructura productiva, que habilite a brindar más trabajo formal bien remunerado, es difícil profundizar una senda de mejora social continua. En cualquier caso, las mejoras experimentadas en el mediano plazo en cuanto a la formalización de la economía, las condiciones de trabajo y los indicadores sociales, habilitan a concluir que cualquier proyecto de transformación

24 Aunque persisten algunos problemas como la segmentación geográfica de la pobreza y su concentración en la edades más tempranas, que además resultan preocupantes para el futuro de la cohesión social en el país. 
productiva no debería comprometer los cimientos de esta institucionalidad laboral y redistributiva.

Durante el año, el gobierno finalmente procesó distintas soluciones a varios temas importantes cuya resolución no podía dilatarse al año previo a las elecciones. En primer lugar, el proceso de caída en la imagen del vicepresidente Raúl Sendic que determinó su renuncia y la llegada a la vicepresidencia de Lucía Topolansky, primera mujer en ocupar ese cargo en la historia del país. Debido a la visibilidad e importancia que han adquirido los gastos discrecionales en el sector público es esperable que el país realice reformas institucionales para mejorar la rendición de cuentas del Estado.

Asimismo, se firmó finalmente el acuerdo entre el gobierno y la empresa finlandesa UPM para la concreción de nuevas inversiones, y se aprobó una ley para la resolución de la situación de alrededor de 30 mil trabajadores que se veían particularmente perjudicados por la reforma del régimen de previsión social que se adoptó en el año 1995.

Cada uno de estos temas implicó tensiones, bien al interior del Ejecutivo bien al interior del partido de gobierno, o en las relaciones entre partido y Ejecutivo. Como ha sucedido en otros momentos, el FA mostró que a diferencia de otros partidos de la región, su influencia en la agenda del gobierno es fundamental para la negociación y resolución de las tensiones que surgen entre los distintos sectores. Al tiempo que el partido constriñe y limita el espacio de decisiones posibles para el Ejecutivo, también se transforma con frecuencia en una arena de discusión, negociación y resolución de conflictos.

La negociación laboral colectiva, por su parte, tuvo un impasse durante el año 2017, a la espera de la mayor ronda de negociación de la historia del país, que tendrá lugar en 2018. El transcurrir de esta ronda de negociación se anticipa como muy importante para la conformación del clima social y político de cara a las elecciones de 2019.

En el plano político aún no se vislumbra un candidato en el partido de gobierno para las próximas elecciones nacionales y la aprobación del gobierno, que había caído fuertemente en 2016, se recuperó parcialmente en 2017 para volver a caer a inicios de 2018. Mientras tanto, en el Partido Nacional, principal representante de la oposición, parece surgir una tercera opción interna organizada en torno a los intendentes del interior del país, que desafía a los dos sectores mayoritarios.

Finalmente, surgieron al final del año conflictos políticos inesperados para el gobierno, en especial con un grupo de productores agropecuarios identificados como el "movimiento de los autoconvocados". Esta es tal vez la principal novedad en la política uruguaya en 2017 y la evolución de este conflicto político en el próximo año será de vital importancia para las posibilidades de continuidad de la izquierda en el gobierno. 


\section{REFERENCIAS}

Alegre, Pablo. 2008. "Democracia y reformas en el Uruguay: un caso de gradualismo perverso." Revista Uruguaya de Ciencia Política 17 (1): 137-158.

Bogliaccini, Juan y Rosario Queirolo. 2017. “Uruguay 2016: Mayorías parlamentarias en jaque y desafíos de revisión para sostener el modelo." Revista de Ciencia Política 37 (2): 589311.

Botinelli, Oscar. 2015. "Las sucesiones presidenciales." Revista de Análisis Político, Opinión Pública y Estudios Sociales, febrero. Recuperado el 29 de marzo de 2018 de https: / /www. factum.uy/analisis/2015/ana150222.php

Brooks, Sarah. 2009. Social Protection and the Market in Latin America. The Transformation of Social Security Institutions. New York: Cambridge University Press.

Búsqueda. 2017, 13 de diciembre. "Astori esta disuesto a renunciar, asumir la banca en el Senado y no votar la ley para los 'cincuentones'." Recuperado el 19 de marzo de 2018 de http://www.busqueda.com.uy/nota/astori-esta-dispuesto-renunciar-asumir-labanca-en-el-senado-y-no-votar-la-ley-para-los

Búsqueda. 2018, 31 de enero. “Presupuesto en 2017: 'Caja Militar' recibió asistencia por casi US\$ 550 millones y el gasto en educación rondó el 4,7\% del PBI." Recuperado el 14 de mayo de 2018 de http:/ / www.busqueda.com.uy/nota/presupuesto-en-2017-caja-militar-recibio-asistencia-por-casi-us-550-millones-y-el-gasto-en

Chasquetti, Daniel. 2014. "Estudio sobre la actividad del parlamento". Convenio Poder Legislativo-Instituto de Ciencia Política, Montevideo. Inédito

Contrato entre la República Oriental del Uruguay UPM. 2017. Recuperado el 28 de marzo de 2018 de https://medios.presidencia.gub.uy/tav_portal/2017/noticias/NO_Y823/ contrato_final.pdf

Crónicas. 2018, 13 de abril. "La pobreza bajó a 7,9\% en 2017 pero la población en asentamientos se mantuvo." Recuperado el 20 de abril de 2018 de http:/ / www.cronicas.com.uy / sociedad/la-pobreza-79-2017-la-poblacion-asentamientos-se-mantuvo /

El Observador. 2017, 8 de diciembre. "Cinco señales de que Astori está con un pie afuera del gobierno." Recuperado el 18 de marzo de 2018 de https://www.elobservador.com. uy/cinco-senales-que-astori-esta-un-pie-afuera-del-gobierno-n1149947

El Observador. 2017, 7 noviembre. "Gobierno firmó acuerdo con UPM para posible instalación de otra planta de celulosa." Recuperado el 19 de marzo de 2018 de https:/ /www.elobservador.com.uy/gobierno-firmo-acuerdo-upm-posible-instalacion-otra-planta-celulosa-n1139564

El País. 2017, 14 de noviembre. "La OIT media, pero posturas del PIT y cámaras no cambian." Recuperado el 18 de marzo de 2018 de https://www.elpais.com.uy/informacion/ oit-media-posturas-pit-camaras-cambian.html

Forteza, Álvaro y Ianina Rossi. 2016. "La jubilación de los "cincuentones"." Recuperado el 28 de marzo de 2018 de http:/ / decon.edu.uy/ alvarof/Cincuentones_20160522.pdf

Informe del PEP. 2017. (In)eficacia del Poder Ejecutivo. Recuperado el 20 de marzo de 2018 de https:/ / parlamentosite.wordpress.com/2017/12/28/ineficacia-del-poder-ejecutivo/

Iversen, Torben. 2005. Capitalism, Democracy and Welfare. New York: Cambridge University Press.

Koolhas, Martín y Matías Nathan. 2013. Inmigrantes internacionales y retornados en Uruguay: magnitud y características. Montevideo, UNFPA-OIM-INE.

La Diaria. 2017, 31 de mayo. "En Reforma de la Caja Militar, triunfó la solución intermedia propuesta por Murro, y el MEF está disconforme." Recuperado el 11 de mayo de 2018 de https://ladiaria.com.uy/articulo/2017/5/en-reforma-de-la-caja-militar-triunfo-la-solucion-intermedia-propuesta-por-murro-y-el-mef-esta-disconforme/

Luna, Juan Pablo. 2010. "The Left Turns: Why They Happened and How They Compare." En Latin America's Left Turns: Politics, Policies, and Trajectories of Change, editado por Maxwell A. Cameron y Eric Hershberg, 23-39. Boulder: Lynne Rienner Publishers. 
Persson, Anna, Bo Rothstein y Jan Teorell. 2013. "Why Anticorruption Reforms Fail-Systemic Corruption as a Collective Action Problem." Governance 26 (3): 449-471.

Pérez, Verónica y Rafael Piñeiro. 2016. “Uruguay 2015: los desafíos de gobernar por izquierda cuando la economía se contrae." Revista de Ciencia Política 36 (1): 339-363.

Presidencia. 2017, 13 de febrero. "Gobierno de Uruguay y firma finlandesa UPM siguen cronograma de negociaciones para instalar planta de celulosa". Recuperado el 19 de marzo de 2018 de https://www.presidencia.gub.uy/comunicacion/comunicacionnoticias/ vazquez-conferencia-finlandia-upm-educacion

Rosenblatt, Fernando, Rafael Piñeiro y Verónica Pérez. 2016. “Internas del Frente Amplio: continuidad en un contexto de cambios." Nueva Sociedad Digital. Recuperado el 25 de marzo de 2018 de http://nuso.org/articulo/internas-del-frente-amplio-continuidad-en-un-contexto-de-cambios /

Rodríguez, Juan Manuel et al. 2016. La sexta ronda de negociación salarial. Montevideo: Facultad de Ciencias Empresariales, Universidad Católica del Uruguay.

Swenson, Peter. 1989. Fair Shares. Ithaca: Cornell University Press.

Traversa, Federico. 2003. "Economía y política en el Uruguay de los noventa." Documento de Trabajo, Instituto Ciencia Política, UDELAR.

Traversa, Federico. 2009. "Economía política de un proyecto socialdemócrata periférico», en Informe de coyuntura." En Varios autores, Encrucijada 2010: la política uruguaya a prue$b a$. Montevideo: Instituto de Ciencia Política, Facultad de Ciencias Sociales y Fin de Siglo.

Fabricio Carneiro. Master en Ciencia Política con especialización en Política Latinoamericana por la Universidad Torcuato Di Tella y estudiante de Doctorado en la misma institución. Profesor e investigador del Instituto de Ciencia Política y de la Facultad de Derecho de la Universidad de la República. Email: fcarneirog@gmail.com

Federico Traversa. Doctor en Ciencia Política por la Universidad de Salamanca. Profesor de la Universidad de la República e Investigador activo de la Agencia Nacional de Investigación e Innovación del Uruguay. Su labor de investigación se aboca principalmente a la Economía Política y Teoría Institucional. Email: traversa@cienciassociales.edu.uy 